\title{
Porosity Study of Synthetic Sandstones by Non-Destructive Nuclear Techniques
}

\author{
Leonardo Carmezini Marques ${ }^{\mathrm{a} *}$, Carlos Roberto Appoloni ${ }^{\mathrm{a}}$, Celso Peres Fernandes ${ }^{\mathrm{b}}$ \\ ${ }^{a}$ Applied Nuclear Physics Laboratory, Physics Department, \\ State University of Londrina - UEL, CP 6001, \\ CEP 86051-990, Londrina, PR, Brazil \\ ${ }^{b}$ Porous Media and Thermophysics Properties Laboratory, \\ Federal University of Santa Catarina - UFSC, CP 476, \\ CEP 88040-900, Florianópolis, SC, Brazil
}

Received: March 29, 2011; Revised: June 22, 2011

\begin{abstract}
In this paper nuclear techniques were used to describe the structural characteristics of ceramic samples. These samples were produced mainly with silica to simulate sandstones. Three sets of samples with different characteristics were analyzed using gamma ray transmission to obtain point by point porosity and X-ray microtomography to obtain the porosity, for $2 \mathrm{D}$ sections and the scanned bulk, as well as the pore size distribution. The transmission results indicated total porosity values of $28.6(4.5) \%$ for the group of samples called ceramic I and 59.6 (2.1)\% for ceramic II. The samples analyzed by microtomography achieved resolutions of 1.7, 0.6 and $1.3 \mu \mathrm{m}$ for the ceramic I, II, and III samples, respectively. This analysis indicated average porosity values of 27.9 (1.4)\% for ceramic I samples and 29.4 (1.2)\% for ceramic III samples.
\end{abstract}

Keywords: ceramics microstructure, mechanical properties, amorphous materials, porosity

\section{Introduction}

Petroleum is currently the main power source, and it is used to provide several products, such as oil, diesel, gas, tar, plastic polymers and drugs. Petroleum and natural gas can be found underground, mainly in sedimentary bases in porous media known as reservoir rocks. These hydrocarbons fill porous spaces between grains or in fissures. During the perforation of a reservoir rock research is carried out to investigate potential accumulative structures, which involves porosity, permeability, saturation and capillarity studies ${ }^{1-3}$. Obtaining samples for this kind of research entails high costs. Therefore, the search for non-destructive techniques to describe the rock reservoir microstructure is of great importance in the extraction of petroleum. A classical method for the structural characterization of rocks is mercury intrusion porosimetry, however, this only gives information on the overall pore content ${ }^{4}$. Also, it is possible to determine the microstructural parameters from 2D images by optical microscopy or scanning electron microscopy. However, these data are not necessarily representative of the bulk material ${ }^{3}$. All these three methodologies involve destruction of the sample.

Gamma ray transmission is a technique which is very suitable for studying porosity. It is a non-destructive and quick method for determining the porosity at the millimetric scale ${ }^{5}$. It is possible to obtain very accurate porosity values for the bulk of samples such as those analyzed herein.

$\mathrm{X}$-ray tomography is a non-destructive technique which was originally developed for medical imaging. It is based on the inhomogeneous absorption of X-rays in bulk material ${ }^{6}$. At present, tomography has progressed due to advances in terms of the X-ray source and detection equipment. This has led to improved resolution and consequently micrometer scale measurements, as well as 3D visualization $^{1,4,6-9}$. Some equipment is even able to measure in nanometer scale $\mathrm{e}^{10,11}$. This technique is able to measure the porosity, permeability, and pore size distribution, among other parameters, from $2 \mathrm{D}$ images of a scanned volume ${ }^{12,13}$. In addition, it is possible to reconstruct part of that volume ${ }^{14,15}$, which allows fluid flow computer simulations ${ }^{3,6}$.

The objective of this research was to evaluate the microstructure of ceramic samples manufactured to simulate sandstones. The parameters studied were porosity, permeability and pore size distribution.

\section{Materials and Methods}

\subsection{Gamma ray transmission}

The experimental set-up consists of a $2 \times 2$ inch $\mathrm{NaI}(\mathrm{Tl})$ scintillation detector and a ${ }^{241} \mathrm{Am}(59.54 \mathrm{keV})$ gamma source, with $100 \mathrm{mCi}$ activity, both filled with a cylindrical lead collimator $9.6 \mathrm{~cm}$ long and with an internal hole of $2 \mathrm{~mm}$ diameter, and a standard gamma ray spectrometry electronic chain connected to a computer. Two kinds of software were used for data acquisition: one to select a window that contains the energy source chosen for the experiments (software MCS-plus), and another to acquire the transmitted ray beam and to control the micrometric table (XZ) of sample position, time, number of points and position of each point (software samara_v2). The measurements and analyses were carried out at the Applied Nuclear Physics Laboratory of the UEL Physics Department.

The gamma ray attenuation is described by the Bear Law ${ }^{16}$ :

$$
I=I_{0} \exp (-\mu x)
$$

where $I_{0}$ is the initial intensity and $I$ is the intensity of gamma rays after attenuation through a medium of length $x$ and $\mu$ is the linear attenuation coefficient of the material.

For the determination of total porosity using gamma ray transmission it is necessary to determine the linear attenuation coefficient for the materials. Therefore, in Equation 1: 


$$
\mu=\frac{1}{x} \ln \left(\frac{I_{0}}{I}\right)
$$

From the particle and measured linear attenuation coefficients, it is possible to calculate the porosity as follows ${ }^{5}$ :

$$
P=\left[\left(\mu_{p}-\mu\right) / \mu_{p}\right] 100
$$

where $P(\%)$ is the porosity of the sample at a point of gamma ray transmission, $\mu\left(\mathrm{cm}^{-1}\right)$ is the linear attenuation coefficient corresponding at this transmission and $\mu_{\mathrm{p}}\left(\mathrm{cm}^{-1}\right)$ is the linear attenuation coefficient of a sample with the same composition and without porosity.

The particle linear attenuation coefficient was obtained with the aid of the software WinXcom ${ }^{5}$. This computer program supplies the particle mass attenuation coefficient taking into account the chemical composition of the sample. The particle linear attenuation coefficient can be calculated as follows:

$$
\mu_{p}=\mu_{p}^{\prime} \rho_{p}
$$

where $\mu_{\mathrm{p}}{ }^{\prime}\left(\mathrm{cm}^{2} \cdot \mathrm{g}^{-1}\right)$ is the particle mass attenuation coefficient of the material that composes the sample and $\rho_{\mathrm{p}}\left(\mathrm{g} \cdot \mathrm{cm}^{-3}\right)$ is the particle density of the material which was supplied by the manufacturer.

\subsection{X-ray microtomography}

An 1172 Skyscan scanner was used to perform the experiment. It comprises an $\mathrm{X}$-ray tube with $\mathrm{W}$ anode operated in the voltage range of $20-100 \mathrm{kV}$ at a power of $10 \mathrm{~W}$. The detector is a $10 \mathrm{Mp}$ (megapixel) CCD camera coupled to the scanner. This set is able to differentiate objects smaller than $1 \mu \mathrm{m}$. Figure 1 shows the basic steps of this setup.

$\mathrm{X}$-ray tomography is based on the distribution of linear attenuation coefficients which can also be described by the Bear Law. The attenuation of the X-ray beam as it passes through the matter originates a projection in the CCD camera, and the set of projections is reconstructed in $2 \mathrm{D}$ sections by a filtered backprojection algorithm ${ }^{17,18}$. This procedure is performed by the NRecon software of the Skyscan series.

Each 2D section is binarized with the Imago software (image analysis software $)^{19}$, so that only pixels corresponding to porous or matrix phase are considered. This procedure is based on the gray-level histogram, where the user selects the threshold for binarization ${ }^{1,15}$. This threshold is selected within a range of 0 to 255 gray tones and thus the porous phase becomes free of noise without damaging the solid phase. The 2D sections obtained are analyzed using the Imago software to determine the total porosity, permeability and pore size distribution of 2D sections and the bulk material. This software was developed at the Laboratory of Porous Media and Thermophysical Properties (LMPT), Department of Mechanical Engineering, Federal University of Santa Catarina, in association with Engineering Simulation and Scientific Software (ESSS).

Porous media, represented in a binary $2 \mathrm{D}$ section, can be characterized by the porous phase function $\mathrm{Z}(\mathrm{x})^{1,19}$ :

$$
Z(x)=\left\{\begin{array}{l}
1 \text { when } x \text { belongs to the porous space } \\
0 \text { in all other cases }
\end{array}\right.
$$

where $x$ denotes the position with respect to an arbitrary origin.

The porosity $\phi$ is defined by the statistical average (denoted by \langle\rangle ), as follows:

$$
\phi=\langle Z(x)\rangle
$$

In the determination of the pore size distribution in binary $2 \mathrm{D}$ sections, the measurement unit consists of the superficial porous area. Therefore, the pore size distribution is calculated as follows:

$$
F(r)=\frac{\phi-\phi(r)}{\phi}
$$

where $\phi$ is the total porosity of the 2D section and $\phi(r)$ is the porosity obtained using the opening operation with a disc (structuring element) of radius $r$.

\subsection{Samples measurements}

For the validation of the gamma ray transmission technique, two materials were analyzed to obtain their linear attenuation coefficients: water and aluminum. The linear attenuation coefficient obtained for each material was compared with the mass attenuation coefficient supplied by the WinXcom software multiplied by the thickness of the material.

Analysis was carried out with ceramic samples manufactured by the company TechMat (Tecnologia de Materiais Ltda, Rio de Janeiro, RJ, Brazil). Samples were mainly manufactured with $\mathrm{SiO}_{2}$, yielding a permeability of $46(9) \mathrm{mD}$ for the group of samples called ceramic I, 550 (20) $\mathrm{mD}$ for ceramic II, both with approximately $100 \%$ of $\mathrm{SiO}_{2}$, and $82(2) \mathrm{mD}$ for ceramic III, with $85 \%$ of $\mathrm{SiO}_{2}$ and $15 \%$ of $\mathrm{Al}_{2} \mathrm{O}_{3}$.

For the determination of total porosity using gamma ray transmission, two sample geometries were analyzed: parallelepiped format with dimensions of $10 \times 1.9 \times 5 \mathrm{~cm}$ and cylindrical format with $3.6 \mathrm{~cm}$ height and $4.9 \mathrm{~cm}$ diameter. All samples were scanned at forty points. The parallelepiped samples were scanned on four levels at ten points, with the objective of determining the point by point porosity. The spacing between two levels and between two measurements at the same level was $1 \mathrm{~cm}$. The cylindrical samples were scanned along ten lines at four points. The angular spacing between two successive lines was eighteen degrees and the spacing between two successive points along the same line was $0.7 \mathrm{~cm}$. The total measurement time was 5.2 hours for the parallelepiped format, 360 seconds for each transmitted beam and 360 seconds for each incident beam measurement. The total measurement time for the cylindrical samples was 11.7 hours, 1020 seconds for each transmitted beam and 180 seconds for each incident beam measurement.

For the validation of the microtomography technique, a nylon thread sample was manufactured. This consisted of a glass cylinder of $6.920(0.009) \mathrm{mm}$ inner diameter filled with 253 nylon threads of 0.355 (0.009) mm diameter. The scanning results were compared with the geometric calculation. The acquisition parameters for this sample were $70 \mathrm{kV} / 141 \mu \mathrm{A}$ voltage and current, respectively; $5.0 \mu \mathrm{m}$ spatial resolution, 5 frames, 0.25 degrees of angular step, 180 rotation degrees, $2360 \mathrm{~ms}$ exposure time, $1048 \times 2000$ pixels on the CCD camera and a $1 \mathrm{~mm}$ aluminum filter in front of the CCD camera.

For the microtomographic experiment, one parallelepiped with dimensions of $0.6 \times 0.6 \times 1.2 \mathrm{~cm}$ was cut from an original parallelepiped of $1 \times 1 \times 3 \mathrm{~cm}$. This procedure was carried out to simplify the acquisition. Table 1 summarizes the acquisition parameters of the samples. Some common parameters were $1048 \times 2000$ pixels on the CCD camera and an aluminum filter of $1 \mathrm{~mm}$ thickness to minimize the beam hardening ${ }^{20}$.

\section{Results and Discussion}

\subsection{Gamma ray transmission}

Table 2 shows the measured values obtained for the validation samples and those obtained with the WinXcom software. Similar 

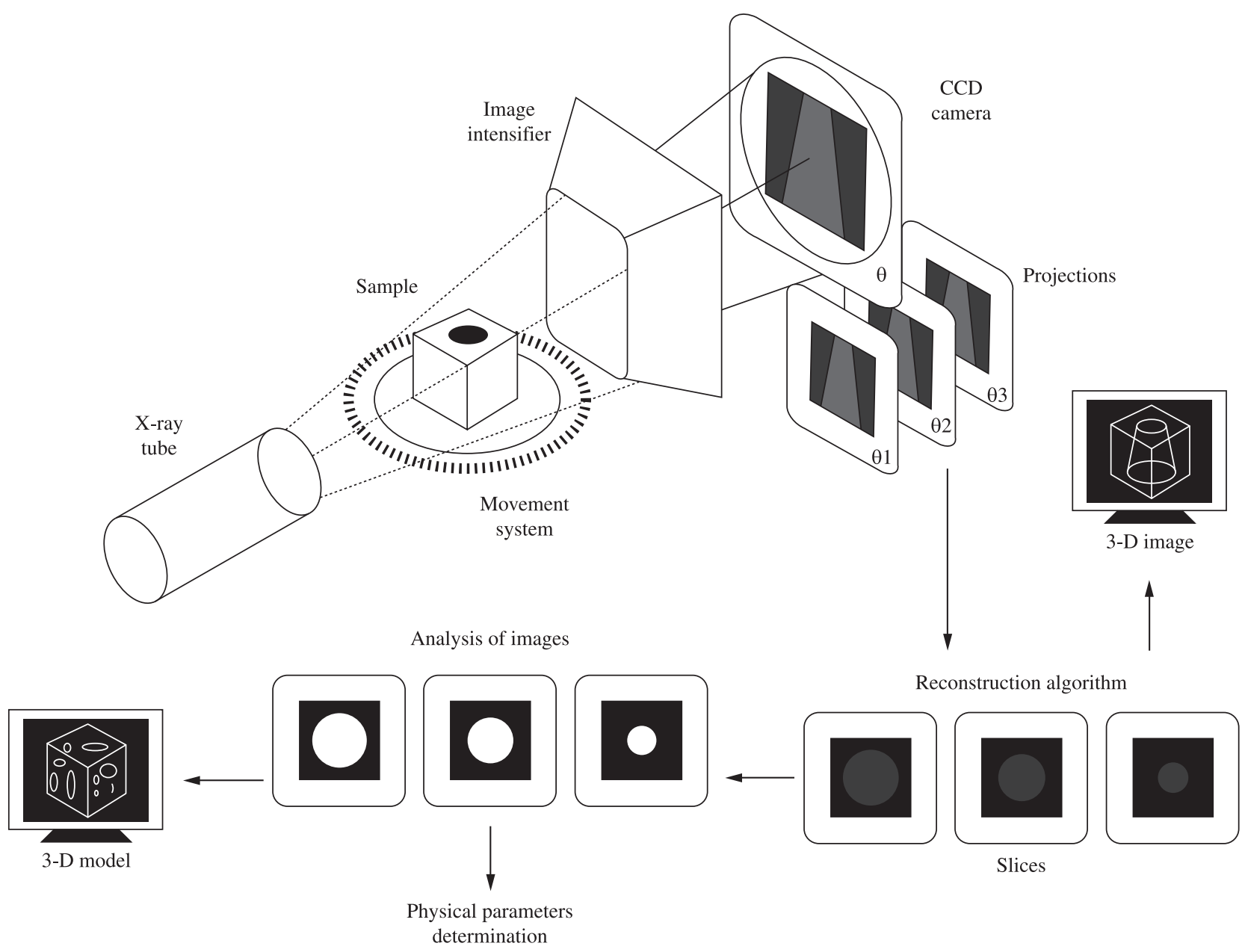

Figure 1. Skyscan 1172: Microtomography steps.

results for the linear attenuation coefficient of water were obtained by Ferraz ${ }^{21}, 0.200(0.002) \mathrm{cm}^{-1}$ and Pöttker ${ }^{22}, 0.1971(0.0005) \mathrm{cm}^{-1}$. The result for the linear attenuation coefficient of aluminum was in agreement with that obtained using WinXcom. Therefore, it was possible to verify the good alignment of the gamma ray transmission equipment.

The particle density value for ceramic I samples is $2.201 \mathrm{~g} . \mathrm{cm}^{-3}$, as supplied by the manufacturer. Based on this density value the WinXcom software provided a particle linear attenuation coefficient for the ceramic samples of $0.559 \mathrm{~cm}^{-1}$. For ceramic II samples, the particle density is $2.214 \mathrm{~g} . \mathrm{cm}^{-3}$, and the particle linear attenuation coefficient is $0.562 \mathrm{~cm}^{-1}$.

Figure 2 shows point to point porosity values for parallelepiped and cylindrical samples of ceramic I. In Figure $2 \mathrm{a}$ and $\mathrm{b}$, the porosity values for points in the same position at different levels can be observed. The parallelepiped samples presented the highest and lowest dispersion in the porosity values for P1-I and P2-I samples, respectively. At only one point the P1-I sample presented an outlier porosity value in the same position, corresponding to the $6 \mathrm{~cm}$ position as indicated by an arrow. In Figure $2 \mathrm{c}$ and d, a lower dispersion of the porosity values can be noted for the cylindrical samples than for the parallelepiped samples, mainly for sample C2-I. This is verified by the standard deviation values in Table 3. This lower dispersion may occur because the points measured on the cylindrical samples were closer than those of the parallelepiped samples due to the measurement set-up and the smaller area of the cylindrical sample.
Table 1. Main acquisition parameters.

\begin{tabular}{lccccc}
\hline Sample & $\begin{array}{c}\text { Voltage } \\
(\mathrm{kV})\end{array}$ & $\begin{array}{c}\text { Resolution } \\
(\mu \mathrm{m})\end{array}$ & $\begin{array}{c}\text { Exposure } \\
\text { time } \\
(\mathrm{ms})\end{array}$ & $\begin{array}{c}\text { Angular } \\
\text { step } \\
(\text { degrees })\end{array}$ & Frames \\
\hline Ceramic I & 59 & 1.73 & 2655 & 0.40 & 4 \\
Ceramic II & 80 & 0.64 & 8835 & 0.25 & 5 \\
Ceramic III & 59 & 1.28 & 2655 & 0.25 & 5 \\
\hline
\end{tabular}

Table 2. Results obtained for the gamma ray transmission validation.

\begin{tabular}{ccc}
\hline Materials & $\mu$ measured $\left(\mathrm{cm}^{-1}\right)$ & $\mu$ WinXcom $\left(\mathrm{cm}^{-1}\right)$ \\
\hline Water & $0.202(0.002)$ & 0.207 \\
Aluminum & $0.74(0.06)$ & 0.76 \\
\hline
\end{tabular}

Table 3 shows the average porosity values for each sample and the global porosity for each form of ceramic I. A good agreement in the average porosity results is observed for different parallelepiped samples and for different cylindrical samples, as well as for the global porosity of the two sample forms. Nevertheless, a tendency toward lower results indicates lower porosity in the cylindrical than in the parallelepiped form. However, the results for both sample forms were in agreement with the porosity value provided by the manufacturer $(28.5 \%)$. 


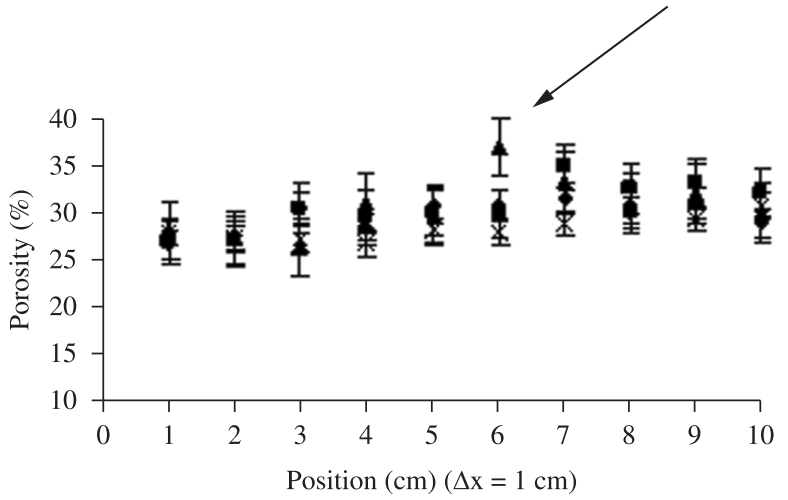

(a)

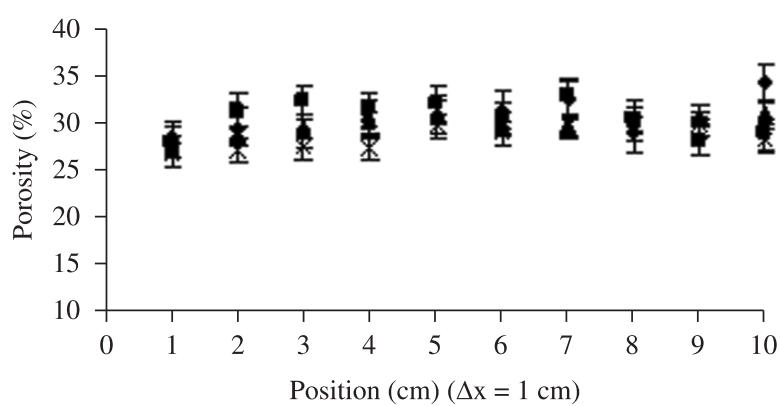

(b)

- Level 1 — Level 2 \ Level $3 \times$ Level 4

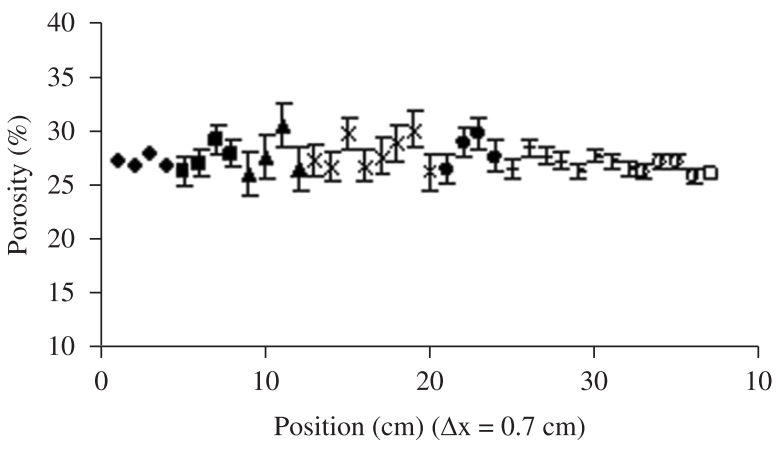

(d)

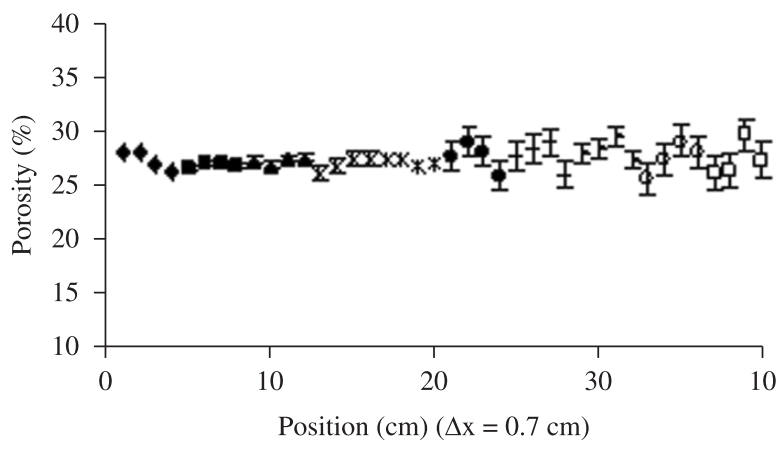

(d)

$\bullet$ Line $1 \square$ Line $2 \Delta$ Line $3 \times$ Line $4 *$ Line $5 \bullet$ Line $6+$ Line $7 \quad$ Line $8 \quad$ Line $9 \quad \square$ Line 10

Figure 2. a) and b) Point to point porosity for P1-I and P2-I parallelepiped levels, respectively; and c) and d) point to point porosity for C1-I and C2-I cylinder lines, respectively.

Table 4 shows the porosity values for parallelepiped and cylindrical samples of ceramic II, respectively. A good agreement between the results for the parallelepiped samples and the porosity values stated by the manufacturer $(56.5 \%)$ was verified. However, there was poor agreement between the results for the cylindrical samples and the porosity values given by the manufacturer. The methodology used by the manufacturer to obtain the sample characteristics, such as particle density and porosity, was the Arquimedes principle ${ }^{23,24}$. This methodology employs sample immersion in liquid. Therefore, the liquid phase needs to reach all pores to supply the correct porosity value. This may explain the lower porosity value supplied by the manufacturer compared with the results of this study.

\subsection{X-ray microtomography}

Figure $3 \mathrm{a}$ shows a 2D image of the nylon thread samples manufactured for the porosity test. The threshold selected for the binarization of this sample was 21 and a total of $4012 \mathrm{D}$ images were obtained. Four sets of 100 2D images were used for the analysis. This procedure was applied due to the limitation of the Imago software when dealing with large quantities of images. Figure $3 \mathrm{~b}$ shows the porosity value for each $2 \mathrm{D}$ image. Each $2 \mathrm{D}$ porosity value has a $0.5 \%$ contrast resolution. The average porosity value was $30.4(0.1) \%$. Erosion and dilation filters, respectively, were used on the binarized image due to the presence of noise. However, some imaging noise remained which caused a difference in the porosity values. The geometric porosity calculation obtained for this test sample was 33.4
Table 3. Porosity results for parallelepiped and cylindrical samples of ceramic I.

\begin{tabular}{ccccc}
\hline \multicolumn{2}{c}{ Parallelepiped } & & \multicolumn{2}{c}{ Cylindrical } \\
\cline { 1 - 2 } \cline { 5 - 5 } Samples & Porosity (\%) & & Samples & Porosity $(\%)$ \\
\hline P1-I & $29.8(4.7)$ & & C1-I & $27.2(2.4)$ \\
P2-I & $29.8(3.1)$ & & C2-I & $27.2(1.9)$ \\
P3-I & $29.6(4.4)$ & & C3-I & $26.6(2.2)$ \\
P4-I & $30.5(4.3)$ & & - & - \\
Global & $29.9(4.1)$ & & Global & $27.0(2.2)$ \\
\hline
\end{tabular}

Table 4. Porosity results for parallelepiped and cylindrical samples of ceramic II.

\begin{tabular}{ccccc}
\hline \multicolumn{2}{c}{ Parallelepiped } & & \multicolumn{2}{c}{ Cylindrical } \\
\cline { 1 - 2 } \cline { 5 - 6 } Samples & Porosity (\%) & & Samples & Porosity (\%) \\
\hline P1-II & $59.8(1.4)$ & & C1-II & $59.3(2.4)$ \\
P2-II & $60.4(1.7)$ & & C2-II & $59.3(1.4)$ \\
& & & C3-II & $59.0(2.2)$ \\
Global & $60.1(4.1)$ & & Global & $59.2(2.1)$ \\
\hline
\end{tabular}

(3.4)\%. Thus, the average porosity value obtained from the X-ray microtomography was in agreement with the geometric porosity.

The selected thresholds for ceramic I and III samples were 146 and 103, respectively. The images obtained for ceramic II were 
weak due to the poor contrast resolution achieved with the parameters chosen.

Figure 4a shows a 2D image obtained with the projections reconstruction for ceramic I and (b) shows the selected area to the "Imago" software analyses. This figure shows a heterogeneity that caused higher porosity values.

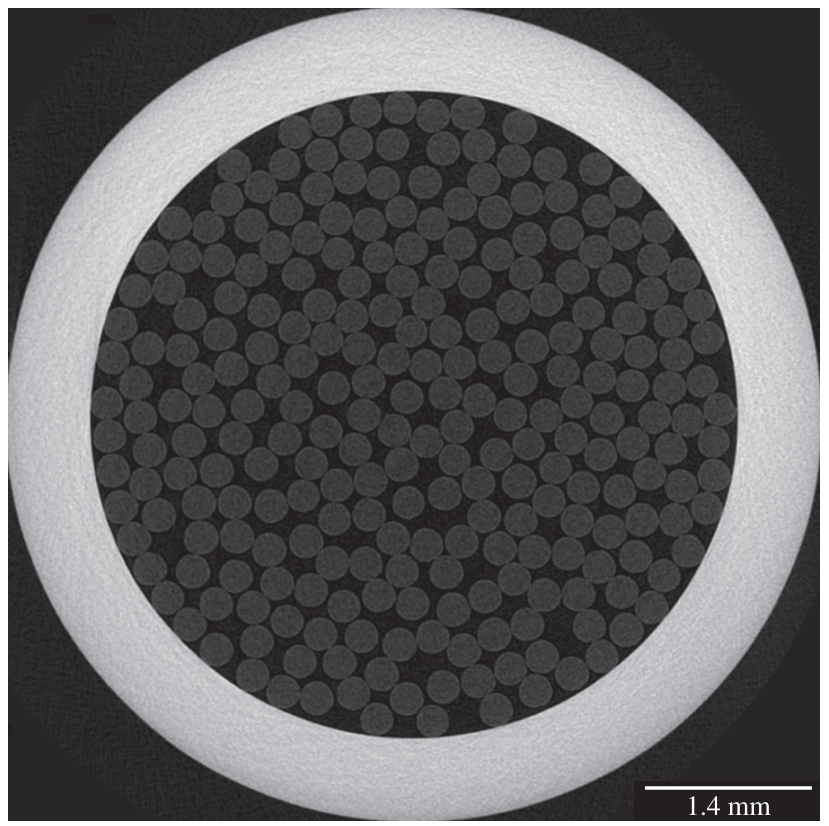

(a)
Figure 5 shows the 2D porosity value for each ceramic I 2D image. The average porosity value for this sample was $27.9(1.4) \%$. However, it is possible to differentiate three regions. The first is the most homogenous, 34 to 646 2D images, with $27.5 \%$ average porosity. The second shows some heterogeneity related to Figure 6, 647 to 788 2D images, with $29.1 \%$ average porosity. The rectangle

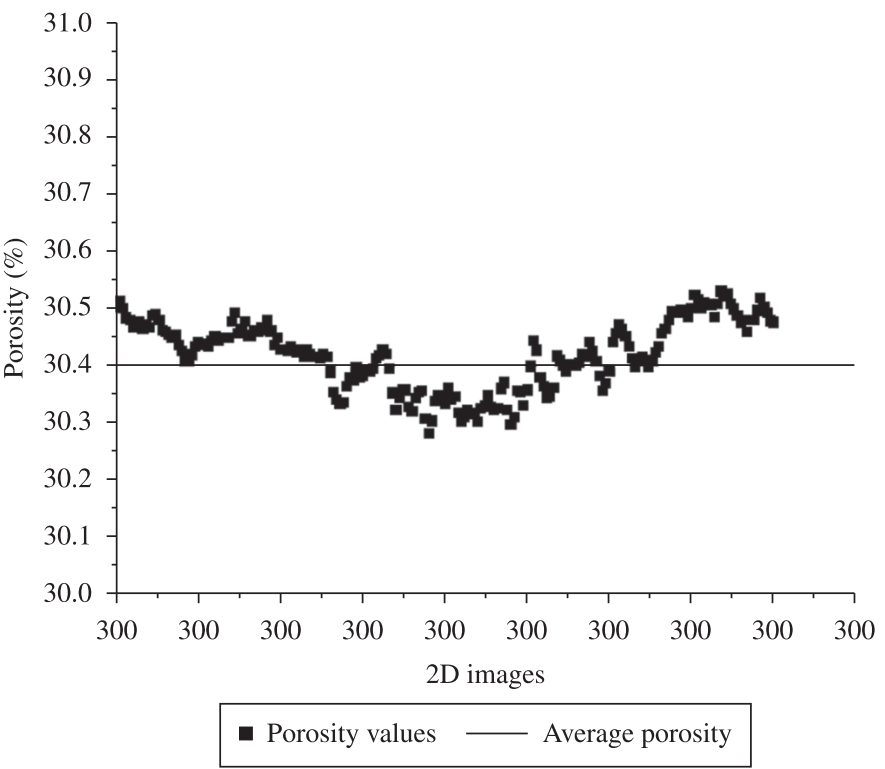

(b)

Figure 3. a) 2D image; and b) porosity value obtained for each $2 \mathrm{D}$ image of the nylon thread sample.

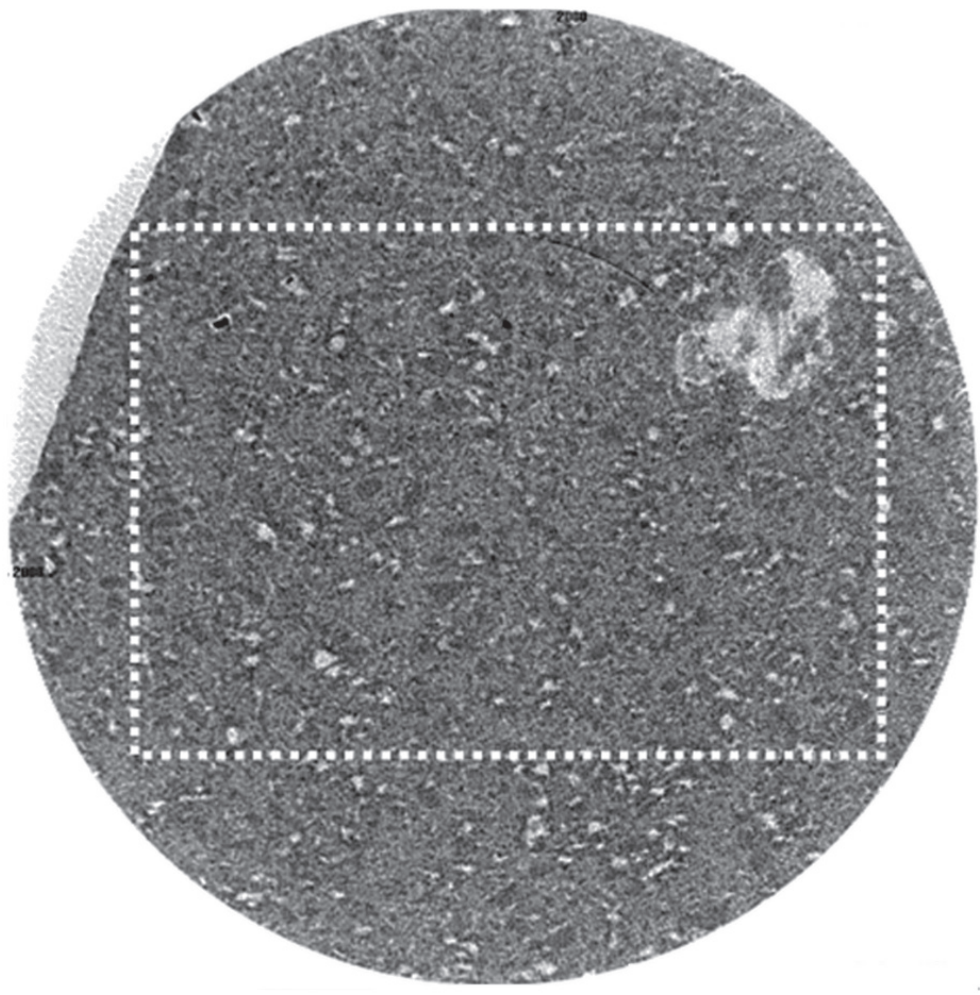

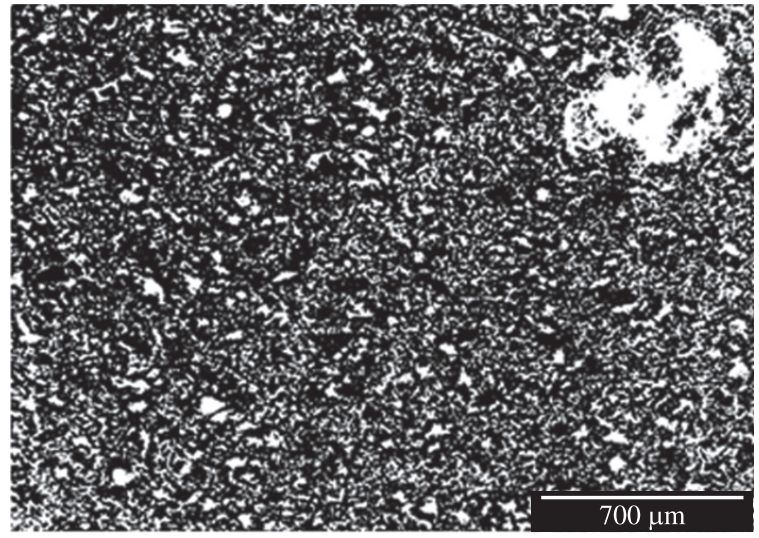

(b)

(a)

Figure 4. a) The 681 2D image; and b) binarized selection of this image at the 146 gray level for the ceramic I sample. 
indicates the greatest influence of the heterogeneity and the third region includes 789 to $10112 \mathrm{D}$ images, with $28.2 \%$ average porosity. The average permeability value obtained for the ceramic I sample was 73 (6) $\mathrm{mD}$. This result showed poor agreement with that supplied by the manufacturer (46 (9) $\mathrm{mD}$ ). The Imago software does not perform well in computing the permeability for complex samples, which could explain this difference. This problem can be attributed to two factors. Firstly, some spurious points are created on all 2D images during the binarization process. Although these artifacts do not cause significant changes in the determination of the porosity or pore size distribution, they can influence significantly the permeability values. Secondly, the methodology employed by the Imago software was created considering an isotropic medium ${ }^{19}$, which is not exactly the case.

Figure 6 shows the average pore size distribution for the ceramic I sample. The detail shows the frequency for 20 to $60 \mu \mathrm{m}$ pore radii. This distribution shows that $66 \%$ of pores possess radius of 3.4 to $6.9 \mu \mathrm{m}$. In addition, the pores with radii shorter than $1.7 \mu \mathrm{m}$, using spatial resolution, could not be quantified.

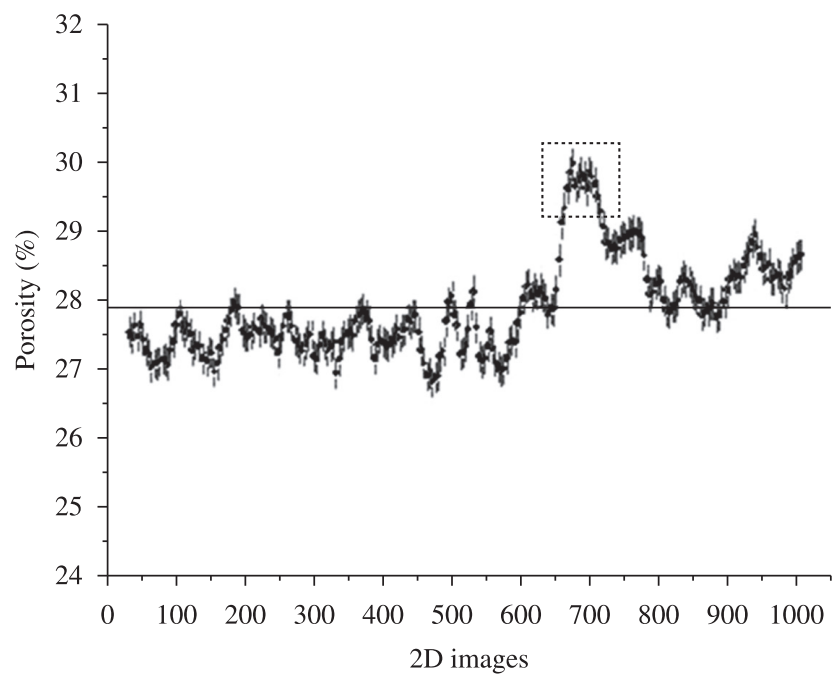

- Porosity values — Average porosity I Statical error

Figure 5. Porosity value for each $2 \mathrm{D}$ image of ceramic I sample. Horizontal line shows average porosity value.

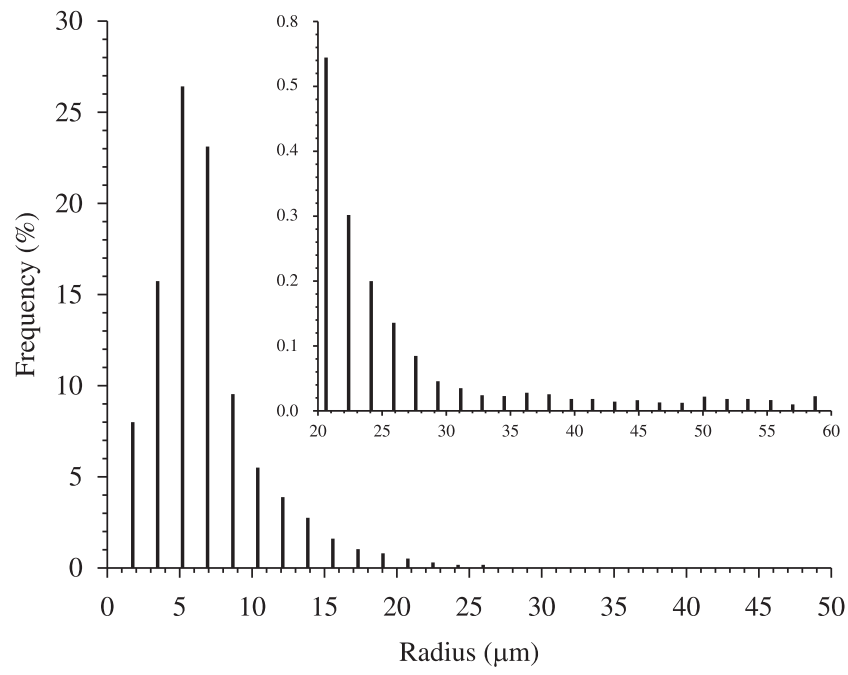

Figure 6. Pore size distribution for ceramic I sample.

Table 5. Porosity values obtained by different methods for ceramic I sample.

\begin{tabular}{llc}
\hline \multicolumn{1}{c}{ Method } & \multicolumn{1}{c}{ Sample } & Global Porosity (\%) \\
\hline Gamma ray transmission & Parallelepiped & $29.9(4.1)$ \\
& Cylinder & $27.0(2.2)$ \\
X-ray microtomography & & $27.9(1.4)$ \\
Manufacturer & & 28.5 \\
\hline
\end{tabular}

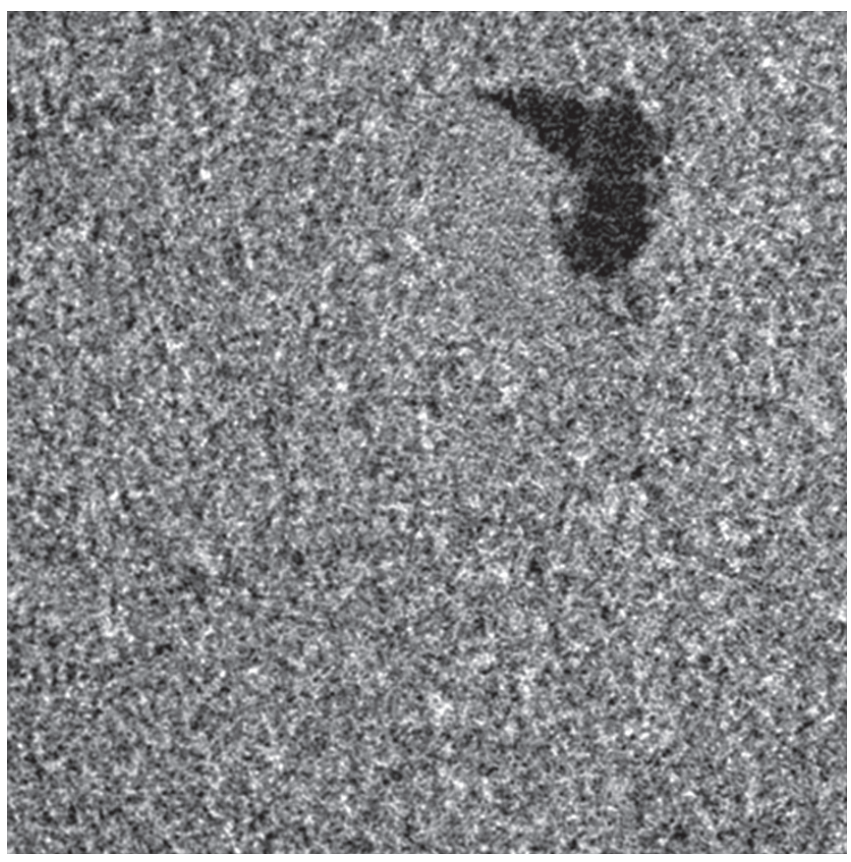

(a)

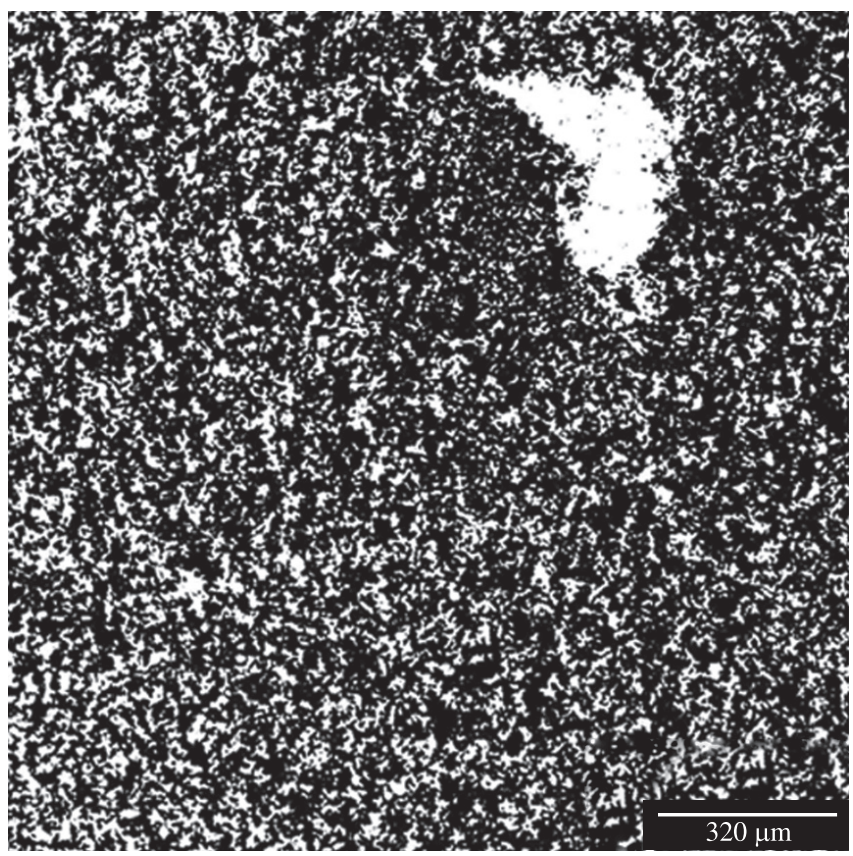

(b)

Figure 7. a) The 669 2D image; and b) binarized selection of this image at 103 gray level for ceramic III sample. 
Table 5 shows the porosity values obtained by gamma ray transmission and X-ray microtomography and those supplied by the manufacturer. The results are in good agreement, particularly the $\mathrm{X}$-ray microtomography and gamma ray transmission results for the cylindrical sample.

Figure $7 \mathrm{a}$ shows a $2 \mathrm{D}$ image obtained with the projection reconstruction for ceramic III and $b$ shows its binarized $2 \mathrm{D}$ image. The 2D image and the binarized image have the same area because an ROI reconstruction parameter was selected. As in the case of ceramic I, ceramic III also shows heterogeneity. However, ceramic III has the densest region, as can be seen on the left side of the hole shown in figure.

Figure 8 shows the $2 \mathrm{D}$ porosity value for each $2 \mathrm{D}$ image of ceramic III. The average porosity value for this sample was 29.4 (1.2)\%. The

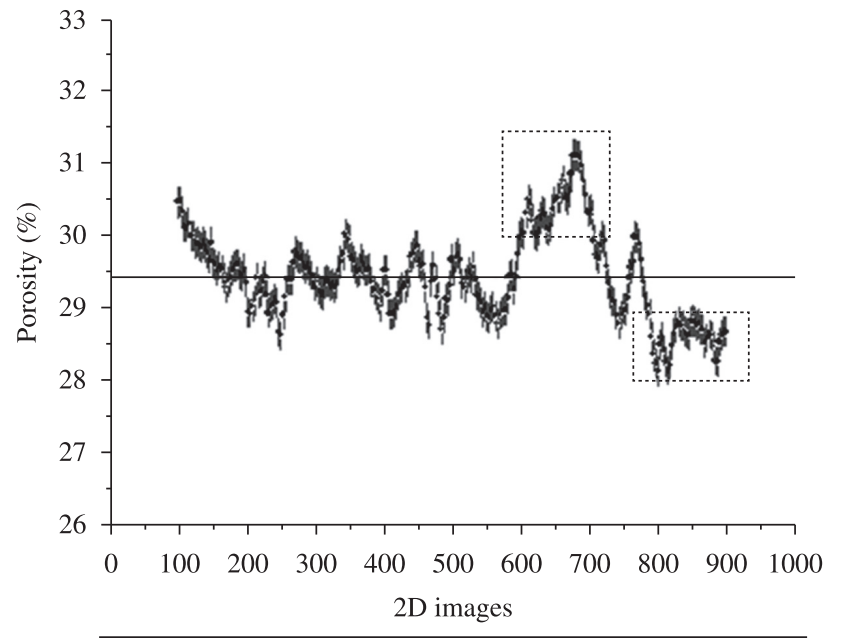

- Porosity values — Average porosity I Statical error

Figure 8. Porosity value for each $2 \mathrm{D}$ image of ceramic III sample. Horizontal line shows average porosity value.

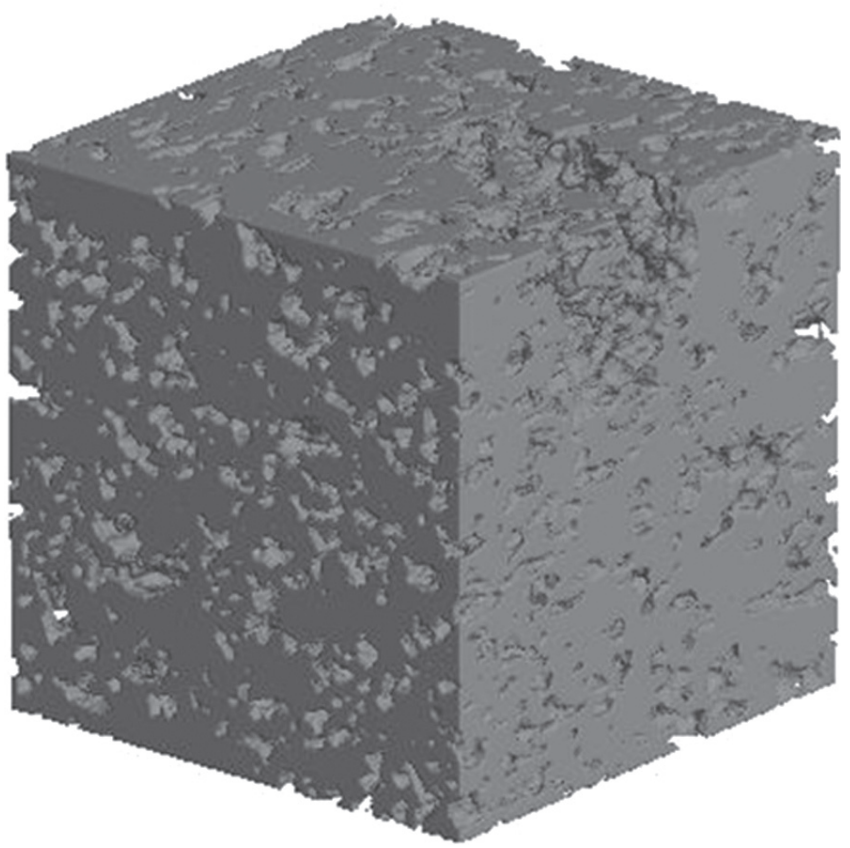

(a) region scanned is characterized by two heterogeneities. The first is a hole occurring on 575 to $9002 \mathrm{D}$ images and the second is a dense region present on 687 to $9002 \mathrm{D}$ images. The upper rectangle indicates a greater influence of the hole and the lower rectangle a greater influence of the dense region. A third region on 789 to $10112 \mathrm{D}$ images had an average porosity of $28.2 \%$. The average permeability value for the ceramic III sample was 49 (4) $\mathrm{mD}$. As in the case of the ceramic I sample, this result for ceramic III showed poor agreement with the value supplied by the manufacturer $(82(2) \mathrm{mD})$.

Figure 9 presents the average pore size distribution for the ceramic III sample. The frequency for 10 to $50 \mu \mathrm{m}$ pore radii is shown in the detail. This distribution shows that $78 \%$ of pores have radii of 2.5 to $6.4 \mu \mathrm{m}$. Furthermore, the pores with radii shorter than $1.3 \mu \mathrm{m}$, using spatial resolution, could not be quantified.

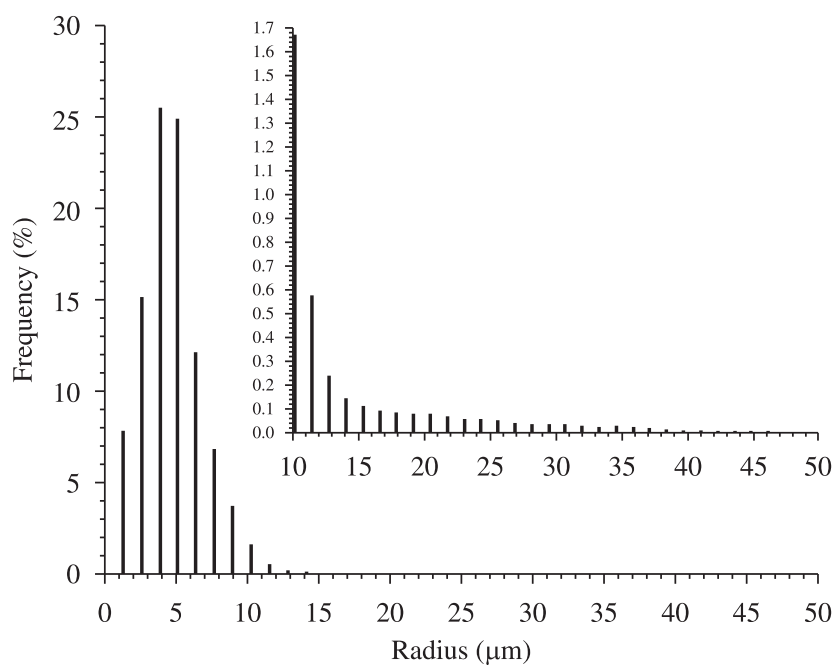

Figure 9. Pore size distribution for ceramic III sample.

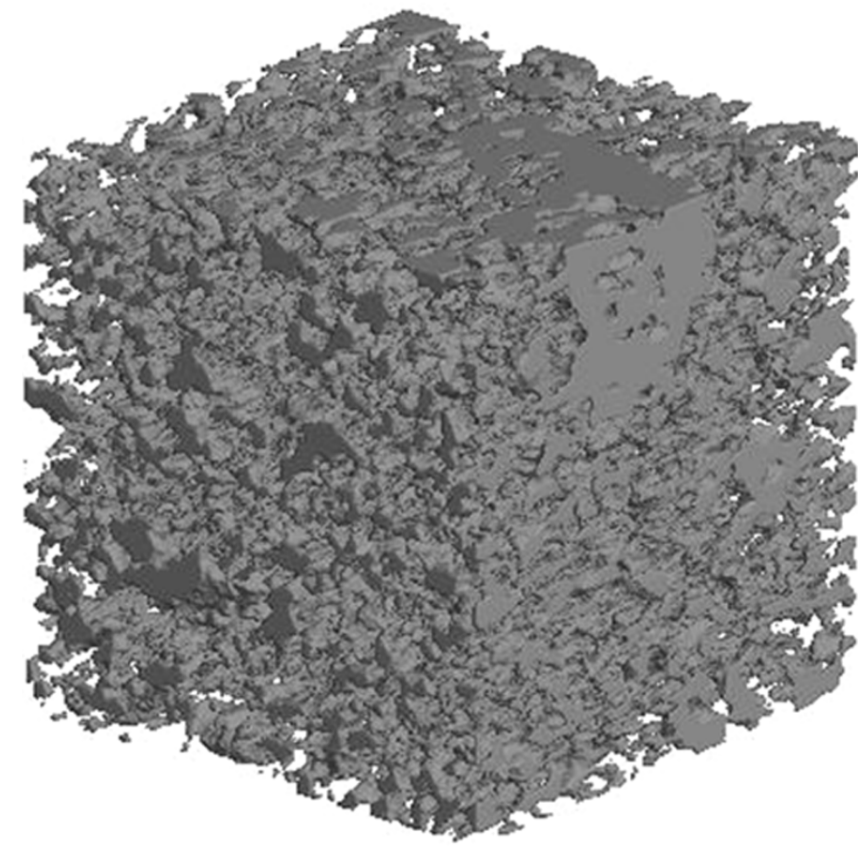

(b)

Figure 10. 3D images $\left(401 \mu \mathrm{m}^{3}\right)$ reconstructed for ceramic I sample a) solid phase; and b) porous phase. 


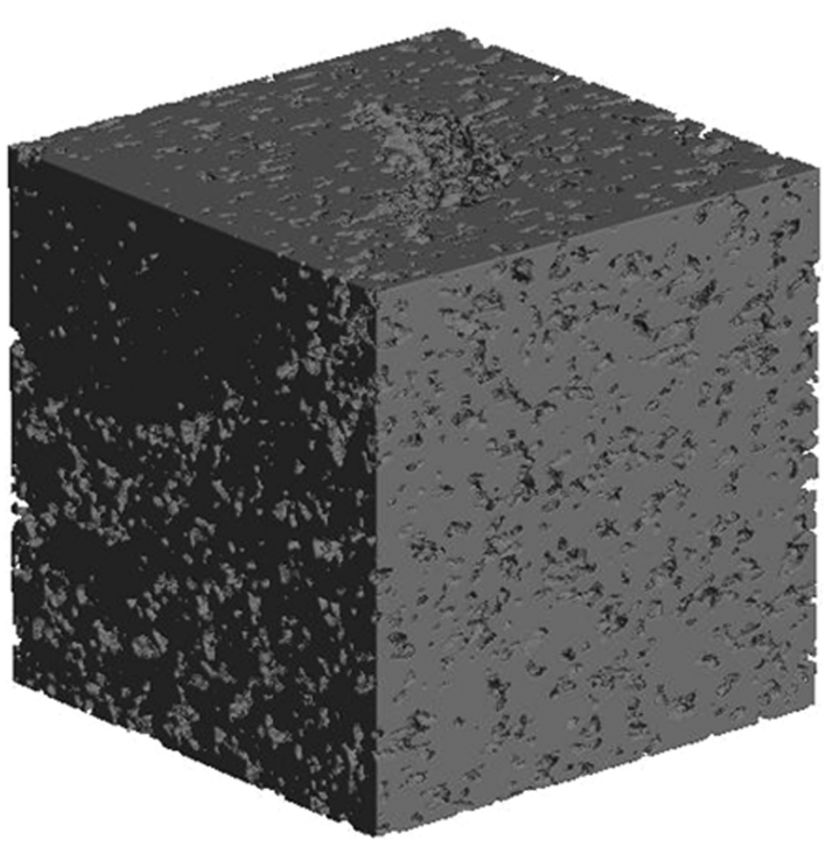

(a)

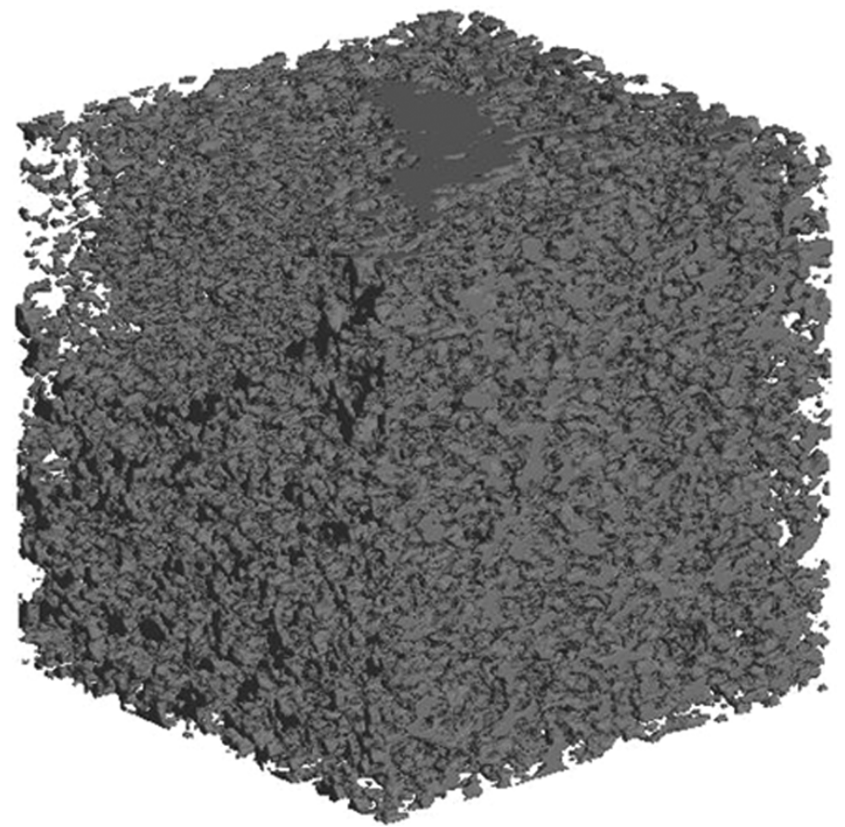

(b)

Figure 11. 3D images $\left(400 \mu \mathrm{m}^{3}\right)$ reconstructed for ceramic III sample a) solid phase; and b) porous phase.

Figure 10 shows the $3 \mathrm{D}$ reconstruction of the ceramic I $2 \mathrm{D}$ images. The heterogeneity that led to the higher porosity values can be partially observed. Figure 11 shows the $3 \mathrm{D}$ reconstruction of the ceramic III 2D images. It is possible to observe a few of the holes that caused the higher porosity values, as well as to show the densest region that led to lower porosity values.

\section{Conclusions}

In this paper gamma ray transmission and X-ray microtomography techniques were used to carry out the structural analysis of ceramic samples. Parallel results for a nylon thread sample show the capacity of the X-ray microtomography to reconstruct 2D images as well as to quantify the structural parameters of porous materials such as ceramic samples. The results also show the influence of the degree of noise on the porosity values. These results could be bettered with the improvement of parameters, such as $360^{\circ}$ rotation.

The agreement in the results for the ceramic I samples shows that both techniques are appropriate for studying this kind of material, because the gamma ray transmission porosity values confirm those obtained by X-ray microtomography, and the 2D and 3D images provide an understanding of the porosity profile changes. The higher quality of the $2 \mathrm{D}$ images for the ceramic III sample indicates the importance of determining the parameters applying this methodology. In this study, the low angular steps and the high spatial resolution are responsible for the difference in quality.

The average pore size distribution is a complementary result that accounts for the greater occurrence of high pore radius values. It also indicates that a better spatial resolution should be used.

This paper demonstrates that gamma ray transmission and $\mathrm{X}$-ray microtomography are two techniques which can be used in combination to evaluate ceramic samples.

\section{References}

1. Appoloni CR, Fernandes CP, Innocentini MDM and Macedo A. Ceramic foams porous microstructure characterization by X-ray microtomography. Materials Reserach. 2004; 7(4):557-56. http://dx.doi.org/10.1590/S151614392004000400008
2. Taud H, Martinez-Angeles R, Parrot JF and Hernandez-Escobedo L. Porosity estimation method by X-ray computed tomography. Journal of Petroleum Science \& Engineering. 2005; 47:209-217. http://dx.doi. org/10.1016/j.petrol.2005.03.009

3. Appoloni CR, Rodrigues CRO and Fernandes CP. Porous microstructure characterization of a sandstone reservoir using high-resolution X-ray microtomography. In International Symposium of the Society of Core Analysts; 2005; Toronto, Canada. Toronto: SCA2005-41; 2005.

4. Gallucci E, Scrivener K, Groso A, Stampanoni M and Margaritodo G. 3D experimental investigation of the microstructure of cement pastes using synchrotron X-ray microtomography $(\mu \mathrm{CT})$. Cement and Concrete Research. 2007; 37:360-368. http://dx.doi.org/10.1016/j. cemconres.2006.10.012

5. Appoloni CR and Pöttker WE. Non-destructive porosity profile measurement of amorphous materials by gamma-ray transmission. Applied Radiation and Isotopes. 2004; 61:1133-1138. http://dx.doi. org/10.1016/j.apradiso.2003.12.013

6. Moreno-Atanasio R, Williams RA and Xiaodong J. Combining X-ray microtomography with computer simulation for analysis of granular and porous materials. Particuology. 2010; 8:81-99. http://dx.doi. org/10.1016/j.partic.2010.01.001

7. Per Spanne and Rivers ML. Computerized microtomography using synchrotron radiation from the NSLS. Nuclear Instruments and Methods in Physics Research Section B. 1987; 24-25(part 2):1063-1067.

8. Rabaglino E, Baruchel J, Boller E, Elmoutaouakkil A, Ferrero C, Ronchi $\mathrm{C}$ et al. Study by microtomography of 3D porosity networks in irradiated beryllium. Nuclear Instruments and Methods in Physics Research B. 2003; 200:352-357. http://dx.doi.org/10.1016/S0168-583X(02)01700-7

9. Bernard D, Gendron D, Heintz J, Bordère S and Etourneau J. First direct $3 \mathrm{D}$ visualization of microstructural evolutions during sintering through X-ray computed microtomography. Acta Materialia. 2005; 53:121-128. http://dx.doi.org/10.1016/j.actamat.2004.09.027

10. Tkachuk A, Duewer F, Cui H, Ferser M, Wang S and Yun W. X-ray computed tomography in Zernike phase contrast mode at $8 \mathrm{keV}$ with 50-nm resolution using $\mathrm{Cu}$ rotating anode $\mathrm{x}$-ray source. Zeitschrift für Kristallographie. 2007; 222:650-655. http://dx.doi.org/10.1524/ zkri.2007.222.11.650

11. Xradia, Inc. Available from: <http://www.xradia.com>. 
12. Jones KW, Spanne P, Lidquist WB, Conner WC and Ferrero M. Determination of polymerization particle morphology using synchrotron computed microtomography. Nuclear Instruments and Methods in Physics Research Section B. 1992; 68:105-110. http://dx.doi.org/10.1016/0168583X(92)96059-8

13. Jones KW, Derkar PB, Mahajan D, Lindquist WB and Feng H. Microstructure of natural hydrate host sediments. Nuclear Instruments and Methods in Physics Research B. 2007; 261:504-507. http://dx.doi. org/10.1016/j.nimb.2007.03.032

14. Farber L, Tardos G and Michaels JN. Use of X-ray tomography to study the porosity and morphology of granules. Powder Technology. 2003; 132:57-63. http://dx.doi.org/10.1016/S0032-5910(03)00043-3

15. Linc L and Miller JD. Network analyses of filter cake pore structure by high resolution X-ray microtomography. Chemical Engineering Journal. 2000; 77:79-86. http://dx.doi.org/10.1016/S1385-8947(99)00149-7

16. Demir D and Keles G. Radiation transmission of concrete including boron waste for 59.54 and $80.99 \mathrm{keV}$ gamma rays. Nuclear Instruments and Methods in Physics Research B. 2006; 245:501-504. http://dx.doi. org/10.1016/j.nimb.2005.11.139

17. Kak A C and Slaney M. Principles of computerized tomographic imaging. IEEE Press; 1999.
18. Lame $\mathrm{O}$, Bellet $\mathrm{D}$, Di Michiel $\mathrm{M}$ and Bouvard D. In situ microtomography investigation of metal powder compacts during sintering. Nuclear Instruments and Methods in Physics Research B. 2003; 200:287-294. http://dx.doi.org/10.1016/S0168-583X(02)01690-7

19. Imago. Image Analysis System. Version 2.1.4. Engineering Simulation and Scientific Software Ltda - ESSS; 2002.

20. Ketcham RA and Carlson WD. Acquisition, optimization and interpretation of X-ray computed tomographic imagery: applications to the geosciences. Computers \& Geosciences. 2001; 27:381-400. http://dx.doi.org/10.1016/S0098-3004(00)00116-3

21. Ferraz ES. Simultaneous thickness and damp determination of soils by $137 \mathrm{Cs}$ and $241 \mathrm{Am}$ gamma ray attenuation. [Thesis]. Piracicaba: University of São Paulo; 1974.

22. Pöttker WE. Measurement of amorphous materials porosity by gamma ray transmission. [Thesis]. Londrina: State University of Londrina; 2000.

23. D'Angelo L, D'Onofrio L and Gonzalez G. Nanophase intermetallic FeAl obtained by sintering after mechanical alloying. Journal of Alloys and Compounds. 2009; 483:154-158. http://dx.doi.org/10.1016/j. jallcom.2008.07.208

24. Colle RD, Fortulan CA and Fontes SR. Manufacture of ceramic membranes for application in demulsification process for cross-flow microfiltration. Desalination. 2009; 245:527-532. http://dx.doi. org/10.1016/j.desal.2009.02.016 